\title{
Blastocystis hominis: A Pathogenic Parasite
}

\author{
Ebrahim Badparva ${ }^{1}$ and Farnaz Kheirandish (iD ${ }^{1, *}$ \\ ${ }^{1}$ Department of Parasitology and Mycology, Razi Herbal Medicines Research Center, School of Medicine, Lorestan University of Medical Sciences, Khorramabad, Iran \\ "Corresponding author: Department of Parasitology and Mycology, Razi Herbal Medicines Research Center, School of Medicine, Lorestan University of Medical Sciences, \\ Khorramabad, Iran. Email: kheirandish81@yahoo.com
}

Received 2019 August 25; Revised 2020 June 29; Accepted 2020 July 05.

\begin{abstract}
Background: Blastocystis hominis is recognized as a common intestinal parasite. Some studies have reported the effect of phenotypic, serologic, and biochemical indices on the parasites' pathogenic characteristics.

Objectives: This study aimed to introduce $B$. hominis as a pathogen, trying to change views about this parasite and introduce it as a parasite important in medical sciences.

Methods: An open-ended, language-restricted (English) search was conducted in MEDLINE (PubMed), CINAHL, Scopus, and the Cochrane Library databases (from 1990 to 2018) using specific search criteria to identify Blastocystis spp.

Results: The search of the literature retrieved 158 published articles on Blastocystis spp. Among these articles, the ones related to the pathogenicity of $B$. hominis were selected for further investigations. Results obtained in this study showed that the number of articles within five-year periods had an increasing trend. Also, studies of $B$. hominis have mainly investigated its pathogenic characteristics, accounting for $37.34 \%$ of the studies.

Conclusions: This study showed comprehensive reasons for proving the pathogenesis of the parasite. It is hoped that further studies would fill the existing gaps regarding this parasite and identify its true identity as a medically important parasite.
\end{abstract}

Keywords: Blastocystis, Pathogen Parasite, Host

\section{Background}

The parasite Blastocystis hominis was first reported by a Russian scientist in 1870; but, it was ignored due to the lack of taxonomic position (1). In 1912, it was discovered as a harmless yeast in a stool sample and officially called Blastocystis hominis. Then, it was again neglected for decades because of being harmless (2,3). A scientist named Zierdt, recognized it as a eukaryotic unicellular organism based on morphological characteristics (4), which sparked the first light for studies in this field (5). Then, its taxonomic position was determined as a new kingdom other than that of another organism called stramenopile, which was named chromista in later revisions, based on the genetic characteristics induced by the SSUrRNA gene sequence $(6,7)$.

Nowadays, it is recognized as the most common intestinal parasite (8). Contrary to other intestinal pathogenic parasites, it is becoming more prevalent (9). Countries have been divided into developed (prevalence up to $10 \%$ ) or developing (prevalence between 50 and $60 \%$ ) groups in terms of the prevalence of this parasite (10). The main reason for its increased prevalence is the lack of health improvements (11). Infection is caused via water-resistant cysts, which are divided into two groups:
Thin-walled ones that induce autoinfection inside the host and thick-walled ones that cause direct infection transfer with water and food to others $(10,12)$.

Even though 100 years have passed since its detection, only a few of its indications, such as morphological characteristics, have been described, and other biological indices are not well-defined; therefore, it is called a mysterious parasite $(13,14)$. One of the ambiguities regarding this parasite is its pathogenic characteristics. Various biological studies have recently reported the heterogeneity of this parasite and discovered its different types, which have become a basis for a few epidemiologic and pathogenic studies (8, 15-17). Furthermore, several studies have reported the effect of phenotypic, serologic, and biochemical indices on the parasites' pathogenic characteristics (18).

Until the last decade, $B$. hominis had attracted attention less than what it deserved, and currently, it is receiving no attention in some countries, like Iran, mainly because of the lack of knowledge of this parasite.

\section{Objectives}

The aim of this study, which collected most studies in this field during recent decades, was to introduce B. homi- 
nis as a pathogen, trying to change views about this parasite and introduce it as a parasite with importance for medical sciences.

\section{Methods}

An open-ended, language-restricted (English) search was conducted in MEDLINE (PubMed), CINAHL, Scopus, and the Cochrane Library databases (from 1990 to 2018) using specific search criteria to identify Blastocystis spp. The search of the literature revealed 158 published articles on Blastocystis spp. Among these articles, the ones related to the pathogenicity of Blastocystis hominis were selected for further investigations. Table 1 presents the articles in five-year intervals, which were investigated in the present work. Table 2 shows the scope of the studied articles. Table 3 presents the target populations in the studied articles.

\begin{tabular}{lc}
\hline \multicolumn{2}{l}{ Table 1. The Number of Articles Based on Five-year Intervals } \\
\hline Intervals & Values \\
\hline $\mathbf{1 9 9 0}-\mathbf{1 1 9 4}$ & $1(0.64)$ \\
\hline $\mathbf{1 9 9 5}-\mathbf{1 9 9 9}$ & $15(9.50)$ \\
$\mathbf{2 0 0 0}-\mathbf{2 0 0 4}$ & $25(15.82)$ \\
$\mathbf{2 0 0 5}-\mathbf{2 0 0 9}$ & $70(44.30)$ \\
\hline $\mathbf{2 0 1 0}-\mathbf{2 0 1 4}$ & $39(24.68)$ \\
\hline $\mathbf{2 0 1 4}$ & $8(5.06)$ \\
\hline Total & $158(100)$ \\
\hline
\end{tabular}

${ }^{\mathrm{a}}$ Values are expressed as No. (\%)

\begin{tabular}{lc}
\hline Table 2. The Number and Percentage of Subjects Studied & \\
\hline Subjects & Values \\
\hline Diagnostic & $49(31.01)$ \\
Epidemiological & $40(25.32)$ \\
Pathogenicity & $59(37.34)$ \\
Others & $10(6.33)$ \\
Total & $158(100)$
\end{tabular}

${ }^{\mathrm{a}}$ Values are expressed as No. (\%)

Studies on the pathogenicity of B. hominis have focused on humans infected with this parasite to determine the relationship between the parasite subtype and clinical signs, or laboratory sensitive animals to investigate the clinical signs and pathological and histological changes. Some articles have also focused on case studies (Table 3 ).

\section{Results}

Table 1, shows the number of articles within five-year periods. Table 2 indicates that the studies on $B$. hominis

\begin{tabular}{lc}
\hline Table 3. Studies on the Pathogenicity of Blastocystis Parasite & \\
\hline Study Type & Values \\
\hline Symptomatic individuals & $32(54.24)$ \\
Subtypes & $9(15.25)$ \\
Animals & $12(20.34)$ \\
Others & $6(10.17)$ \\
\hline Total & $59(100)$ \\
\hline
\end{tabular}

${ }^{\mathrm{a}}$ Values are expressed as No. (\%).

have mainly investigated its pathogenic characteristics, with $37.34 \%$ of the studies being focused on this aspect. In the second place are diagnostic articles that have examined the molecular methods in various countries. The epidemiologic studies are ranked third.

Based on Table 3, which presents the articles about the pathogenicity of $B$. hominis, various aspects of this parasite have been investigated and analyzed; in other words, a comprehensive study has been conducted on B. hominis.

\section{Discussion}

The present study was the first work that surveyed $B$. hominis from all various aspects using the collection of related articles published in 1990 - 2018.

This study showed that investigating B. hominis had an ever-increasing trend such that $60 \%$ of the studies have been carried out in the recent decade. Therefore, it can be considered an emerging parasite. Also, a great portion of studies has been conducted on the pathogenic characteristics of this parasite, which is a required field in medical science (19). This confirms the increasing attention to biological studies and their roles in the pathogenesis of the parasite. Thus, the pathogenic characteristics of $B$. hominis are the most important issues that have been investigated (20).

Many studies have introduced $B$. hominis as a potential pathogen (21-25), with digestive symptoms including diarrhea, abdominal pain, anorexia, bloat, fatigue, and extra gastrointestinal symptoms such as urticaria and itchy skin, as well as joint pain $(14,23,26,27)$. As infected people without symptoms are also found, its pathogenesis is unclear and controversial (28). Studies of the pathogenicity of $B$. hominis are classified into two groups based on parasite and host indices.

\subsection{Parasite Indices}

Some people infected with $B$. hominis show no clinical signs of infection, which cannot be a reason for the nonpathogenic characteristics of this parasite, because there are also other pathogenic parasites with similar conditions 
such as Giardia lamblia (in mild infections), Entamoeba histolytica (before E. dispar separation), and Trichomonas vaginalis (before host maturity) (29-31).

On the other hand, it is believed that the increased parasitic load can affect the pathogenicity and clinical signs and induce an acute condition for the disease $(14,32)$, as verified in laboratory mice models (33-36). When the scope of the studies becomes broader, the effective factors in the pathogenicity of $B$. hominis become more apparent; for example, by conducting genetic studies and determining the subtypes of $B$. hominis, it was revealed that some subtypes are pathogenic, like subtype ST1, while others are nonpathogenic, such as subtype ST2 (27,37-39). Pathogenic subtypes vary in various geographical regions (40-44), which indicates that parasitic isolates have potentially different pathogenesis (45).

Phenotype studies have provided much information regarding the parasite. For example, all the isolates causing clinical symptoms in the host can grow in an amoeboid form in the culture medium, which is considered one of the Blastocystosis indices with clinical symptoms (46). This condition might be due to the genetic similarity of $B$. hominis and E. histolytica, as well as the secretion of the hyaluronidase enzyme from the $B$. hominis parasite that destroys proteins in the extracellular matrix and provides the condition for parasite attack. This is because this enzyme is observed at high concentrations in the urine of infected patients. This enzyme is among the pathogenic factors for E. histolytica, which destroys the base of epithelial cells (47).

Pathogenic subtypes have larger sizes and coarser surfaces and grow faster in culture medium when compared to the non-pathogenic subtypes (8). These properties can cause bacteria to have a higher tendency to attach to the parasite surface and produce more immune responses against carbohydrates attached to the bacterial cell wall such that the production of antibody IgG2 in serum and body secretions in pathogenic subtypes is 10 times the nonpathogenic cases; this indicates the immunogenic potential of pathogenic subtypes (48). Other factors like the isoenzyme model (49), the shape of proteins, and serological properties of $B$. hominis can also be used for separating the symptomatic cases from the asymptomatic ones; however, none of them can provide a definitive answer $(18,38$, $50,51)$.

Secretory IgA is considered one of the inhibiting factors; but, $B$. hominis secretes cysteine protease, concentrating in the vacuoles of the parasite, which decomposes secretory IgA and eliminates IgA from its path $(10,19$, 52). Increased secretion of this enzyme leads to greater pathogenicity of the parasite. (35). Then, using carbohydrates such as a-D-mannosyl, a-D-glucosyl, and N-acetylB-D- glucosamine that are present on the cell wall of pathogenic $B$. hominis the parasite attaches to the epithe- lial cells in the intestinal mucosa and has the opportunity to multiply and colonize. (53).

When the above-mentioned glucose bind to concanavalin A (ConA) and helix pomatia agglutinin (HPA), the bound parasites are detectable by fluorescence $\mathrm{mi}$ croscopy; the same is true for the pathogenic strains of $E$. histolytica that produce a large quantity of lipophosphoglycan (LPG) and lipophosphopeptidoglycan (LPPG) and gain the ability to bind to epithelial cells in the intestinal mucosa; however, it is not the case of E. dispar (53). Also, it is similar to the presence of lectin in Acanthamoeba keratitis for binding to enterocytes, which are available in pathogenic forms (19).

Although it has been previously mentioned that $B$. hominis secretes hyaluronidase to provide the condition for the attack (54), this question is always posed whether $B$. hominis has the ability to attack or not. In the intestinal mucosa, there is a skeletal protein called F-action, which firmly holds the mucosa epithelial cells, increases their strength, and decreases permeability. B. hominis disturbs the distribution of this factor and consequently decreases the strength and increases permeability $(35,55,56)$, which eventually results in the disturbed balance of water and electrolytes (57). In addition, B. hominis stimulates the apoptosis of host cells, which disturbs their performance. It is interesting to note that subtype 1 of $B$. hominis shows the highest virulence because it produces more gastrointestinal permeability (37). Increased permeability is also reported in infections with G. lamblia; but, it has not been observed in E. coli (58). Also, the secretion of cytokines IFN$\gamma$, IL-12, and TNF- $\alpha$ disturbs the intestinal mucosa, as shown in the in vitro environment $(53,59)$.

In severe infections of mice with Blastocystis spp., the extreme infiltration of inflammatory cells, lymphocyte accumulation, mucus shedding, and parasite penetration into the intestine's superficial layer and glandular space are reported $(22,36,60)$. The increased levels of leukocytes in the stool have also been reported as one of the criteria for the level of parasite pathogenesis (23). The mechanism of diarrhea, which mostly occurs in immunocompromised patients, is not completely identified (61); however, the poison that causes diarrhea has been found in the filter of culture medium and parasite lysis (5).

The bleeding caused by enteropathy in the rectal area of a four-year-old girl, where $B$. hominis was the only identified agent that penetrated the superficial layer of the intestinal mucosa and glandular space accompanied by the leakage of inflammatory cells, treated by metronidazole, could verify the claim that this parasite can cause such a disorder (21).

This invasion occurs only in the large intestine because no invasion was performed during the injection of Blastocystis cyst with Entamoeba histolytica in golden hamster 
liver. (62).

All of the above-mentioned materials can partly indicate the role of $B$. hominis in the development of clinical symptoms and support its pathogenesis.

\subsection{Host Indices}

Hosts can also play a role in developing a disease. It has been shown that the prevalence of the parasite is higher in those with mental retardation, which can be due to the lack of sanitary considerations among this group, with more pronounced symptoms in patients with the immune system deficiency $(10,14,63,64)$. This indicates that the parasite is opportunistic; however, this claim has been rejected by some other studies $(65,66)$. In a study conducted on mice, it was shown that younger mice were more susceptible to infections with Blastocystis spp. (36). Also, a similar study was conducted on mice infected with Cryptosporidium, which indicated that older mice had higher resistance (67); the author discussed that the host immunity was responsible for this result.

In a study conducted on RN94-9 rats, it was shown that despite the secretion of cytokines IFN- $\gamma$, IL-12, and TNF- $\alpha$ in the intestinal mucosa and the increased levels of goblet cells, no significant changes were observed in colons (33), which indicated the resistance of this type of host, while it caused pathologic changes in the intestine of younger mice $(36,68)$.

Irritable bowel syndrome (IBS) is a digestive disorder with symptoms such as abdominal pain, diarrhea, and constipation. Inflammatory bowel disease (IBD) is also a disease associated with diarrhea and colon lesions with unknown pathogens, which have been related to infection with $B$. hominis in some studies (27, 69-71). In a study conducted in Europe and the Middle East, 30-40\% of the patients were infected with B. hominis (72). In another study, $46 \%$ of the patients with IBS were positive for B. hominis, while only $7 \%$ of the control group had this parasite (73). It was reported that these diseases can result from serine protease, which is secreted by the parasite, and its high level can cause intense neural activity, abdominal pain, muscle cramp, and generalized pains, which are not found in bacterial and viral enteritis (74). Other studies have also demonstrated that some people infected with B. hominis have skin allergy symptoms in the form of an erythema, itching, and urticaria, where the factor is believed to be IgE secreted due to the immune system response to the parasite's surface antigens (75-77).

\section{Conclusions}

Some studies strongly state that $B$. hominis is a pathogen, while others have ambiguities regarding this parasite, and some cases ignore its medical importance. This study aimed to collect comprehensive reasons for proving the pathogenesis of this parasite. It is hoped that further studies would fill the existing gaps regarding this parasite and identify its true identity as a medically important parasite.

\section{Acknowledgments}

The authors sincerely thank all those who helped us in this research.

\section{Footnotes}

Authors' Contribution: Study concept and design: Farnaz Kheirandish and Ebrahim Badparva. Drafting of the manuscript: Ebrahim Badparva. Critical revision of the manuscript for important intellectual content: Farnaz Kheirandish and Ebrahim Badparva. Statistical analysis: Ebrahim Badparva.

Conflict of Interests: The authors declare that there is no conflict of interest.

Ethical Approval: This study was approved by the Ethics Committee of Lorestan University of Medical Sciences

Funding/Support: The authors have no financial interests related to the material in the manuscript.

\section{References}

1. Lesh FA. Massive development of amebas in the large intestine. Fedor Aleksandrovich Lesh (Losch). Am JTrop Med Hyg. 1975;24(3):383-92. doi: 10.4269/ajtmh.1975.24.383. [PubMed:1098489].

2. Doyle PW, Helgason MM, Mathias RG, Proctor EM. Epidemiology and pathogenicity of Blastocystis hominis. J Clin Microbiol. 1990;28(1):11621. doi: 10.1128/JCM.28.1.116-121.1990. [PubMed: 2298869]. [PubMed Central: PMC269548].

3. Moghaddam DD, Ghadirian E, Azami M. Blastocystis hominis and the evaluation of efficacy of metronidazole and trimethoprim/sulfamethoxazole. Parasitol Res. 2005;96(4):273-5. doi: 10.1007/s00436-005-1363-1. [PubMed: 15915364].

4. Zierdt $\mathrm{CH}$, Tan HK. Ultrastructure and light microscope appearance of Blastocystis hominis in a patient with enteric disease. $Z$ Parasitenkd. 1976;50(3):277-83. doi: 10.1007/BF02462972. [PubMed: 997721].

5. Zierdt CH. Blastocystis hominis-past and future. Clin Microbiol Rev. 1991;4(1):61-79. doi: 10.1128/cmr.4.1.61. [PubMed: 2004348]. [PubMed Central: PMC358179].

6. Cavalier-Smith T. A revised six-kingdom system of life. Biol Rev Camb Philos Soc. 1998;73(3):203-66. doi: 10.1017/s0006323198005167. [PubMed: 9809012].

7. Silberman JD, Sogin ML, Leipe DD, Clark CG. Human parasite finds taxonomic home. Nature. 1996;380(6573):398. doi: 10.1038/380398a0. [PubMed: 8602239].

8. Tan KS, Singh M, Yap EH. Recent advances in Blastocystis hominis research: hot spots in terra incognita. Int J Parasitol. 2002;32(7):789-804. doi: 10.1016/s0020-7519(02)00005-x.

9. Basak S, Rajurkar MN, Mallick SK. Detection of Blastocystis hominis: a controversial human pathogen. Parasitol Res. 2014;113(1):261-5. doi: 10.1007/s00436-013-3652-4. [PubMed: 24169810]. 
10. Tan KS. New insights on classification, identification, and clinical relevance of Blastocystis spp. Clin Microbiol Rev. 2008;21(4):639-65. doi: 10.1128/CMR.00022-08. [PubMed: 18854485]. [PubMed Central: PMC2570156].

11. Taamasri P, Mungthin M, Rangsin R, Tongupprakarn B, Areekul W, Leelayoova S. Transmission of intestinal blastocystosis related to the quality of drinking water. Southeast Asian J Trop Med Public Health. 2000;31(1):112-7.

12. Amin OM. Seasonal prevalence of intestinal parasites in the United States during 2000. Am J Trop Med Hyg. 2002;66(6):799-803. doi: 10.4269/ajtmh.2002.66.799. [PubMed:12224595].

13. Lucia JF, Aguilar C, Betran A. Blastocystis hominis colitis in a haemophilic patient as a cause of lower gastrointestinal bleeding. Haemophilia. 2007;13(2):224-5. doi: 10.1111/j.1365-2516.2006.01434.x. [PubMed: 17286783].

14. Stenzel DJ, Boreham PF. Blastocystis hominis revisited. Clin Microbiol Rev. 1996;9(4):563-84. doi: 10.1128/CMR.9.4.563-584.1996. [PubMed: 8894352]. [PubMed Central: PMC172910].

15. Badparva E, Pournia Y, Fallahi S. Prevalence of Blastocystis hominis in Lorestan Province, West of Iran, 2010. Asian J Biol Sci. 2011;5(1):57-61. doi: 10.3923/ajbs.2012.57.61.

16. Badparva E, Sadraee J, Kheirandish F, Frouzandeh M. Genetic diversity of human blastocystis isolates in khorramabad, central iran. Iran J Parasitol. 2014;9(1):44.

17. Badparva E, Fallahi S, Arab-Mazar Z. Blastocystis: Emerging protozoan parasite with high prevalence in Iran. Novelty in Biomedicine. 2015;3(4):214-21.

18. Lanuza MD, Carbajal JA, Villar J, Mir A, Borras R. Soluble-protein and antigenic heterogeneity in axenic Blastocystis hominis isolates: pathogenic implications. Parasitol Res. 1999;85(2):93-7. doi: 10.1007/s004360050515. [PubMed: 9934956].

19. Tan TC, Suresh KG, Smith HV. Phenotypic and genotypic characterisation of Blastocystis hominis isolates implicates subtype 3 as a subtype with pathogenic potential. Parasitol Res. 2008;104(1):85-93. doi: 10.1007/s00436-008-1163-5. [PubMed: 18795333]

20. Stark D, van Hal S, Marriott D, Ellis J, Harkness J. Irritable bowel syndrome: a review on the role of intestinal protozoa and the importance of their detection and diagnosis. Int J Parasitol. 2007;37(1):11-20. doi: 10.1016/j.ijpara.2006.09.009. [PubMed: 17070814].

21. al-Tawil YS, Gilger MA, Gopalakrishna GS, Langston C, Bommer KE. Invasive Blastocystis hominis infection in a child. Arch Pediatr Adolesc Med. 1994;148(8):882-5. doi: 10.1001/archpedi.1994.02170080112026. [PubMed: 8044274]

22. Elwakil HS, Hewedi IH. Pathogenic potential of Blastocystis hominis in laboratory mice. Parasitol Res. 2010;107(3):685-9. doi: 10.1007/s00436-010-1922-y. [PubMed: 20499092].

23. Kaya S, Cetin ES, Aridogan BC, Arikan S, Demirci M. Pathogenicity of Blastocystis hominis, a clinical reevaluation. Turkiye Parazitol Derg. 2007;31(3):184-7.

24. Javaherizadeh H, Khademvatan S, Soltani S, Torabizadeh M, Yousefi E. Distribution of haematological indices among subjects with Blastocystis hominis infection compared to controls. Prz Gastroenterol. 2014;9(1):38-42. doi: 10.5114/pg.2014.40849. [PubMed: 24868297] [PubMed Central: PMC4027846].

25. Cassano N, Scoppio BM, Loviglio MC, Vena GA. Remission of delayed pressure urticaria after eradication of Blastocystis hominis. Acta Derm Venereol. 2005;85(4):357-8. doi: 10.1080/00015550510026695. [PubMed: 16191864]

26. Zierdt CH, Zierdt WS, Nagy B. Enzyme-linked immunosorbent assay for detection of serum antibody to Blastocystis hominis in symptomatic infections. J Parasitol. 1995;81(1):127-9. [PubMed: 7876972].

27. Jones MS, Whipps CM, Ganac RD, Hudson NR, Boorom K. Association of Blastocystis subtype 3 and 1 with patients from an Oregon community presenting with chronic gastrointestinal illness. Parasitol Res. 2009;104(2):341-5. doi: 10.1007/s00436-008-1198-7. [PubMed: 18923844].

28. Dogruman-Al F, Kustimur S, Yoshikawa H, Tuncer C, Simsek Z, Tanyuksel M, et al. Blastocystis subtypes in irritable bowel syndrome and inflammatory bowel disease in Ankara, Turkey. Mem Inst Oswaldo Cruz. 2009;104(5):724-7. doi: 10.1590/s0074-02762009000500011. [PubMed: 19820833].

29. Eroglu F, Genc A, Elgun G, Koltas IS. Identification of Blastocystis hominis isolates from asymptomatic and symptomatic patients by PCR. Parasitol Res. 2009;105(6):1589-92. doi:10.1007/s00436-009-15956. [PubMed: 19685075].

30. Reed SL, Keene WE, McKerrow JH. Thiol proteinase expression and pathogenicity of Entamoeba histolytica. J Clin Microbiol. 1989;27(12):2772-7. doi: 10.1128/JCM.27.12.2772-2777.1989. [PubMed: 2556432]. [PubMed Central: PMC267124].

31. Guimaraes S, Sogayar MI, Franco MF. Protease activity in Giardia duodenalis trophozoites of axenic strains isolated from symptomatic and asymptomatic patients. Mem Inst Oswaldo Cruz. 2003;98(1):77-81. doi: 10.1590/s0074-02762003000100011. [PubMed: 12700865].

32. Sheehan DJ, Raucher BG, McKitrick JC. Association of Blastocystis hominis with signs and symptoms of human disease. J Clin Microbiol. 1986;24(4):548-50. doi: 10.1128/JCM.24.4.548-550.1986. [PubMed: 3771743]. [PubMed Central: PMC268968].

33. Iguchi A, Yoshikawa H, Yamada M, Kimata I, Arizono N. Expression of interferon gamma and proinflammatory cytokines in the cecal mucosa of rats experimentally infected with Blastocystis sp. strain RN949. Parasitol Res. 2009;105(1):135-40. doi: 10.1007/s00436-009-1373-5. [PubMed: 19255785].

34. Puthia MK, Sio SW, Lu J, Tan KS. Blastocystis ratti induces contactindependent apoptosis, F-actin rearrangement, and barrier function disruption in IEC-6 cells. Infect Immun. 2006;74(7):4114-23. doi: 10.1128/IAI.00328-06. [PubMed: 16790785]. [PubMed Central: PMC1489721].

35. Puthia MK, Lu J, Tan KS. Blastocystis ratti contains cysteine proteases that mediate interleukin-8 response from human intestinal epithelial cells in an NF-kappaB-dependent manner. Eukaryot Cell. 2008;7(3):435-43. doi: 10.1128/EC.00371-07. [PubMed: 18156286]. [PubMed Central: PMC2268520]

36. Moe KT, Singh M, Howe J, Ho LC, Tan SW, Chen XQ, et al. Experimental Blastocystis hominis infection in laboratory mice. Parasitol Res. 1997;83(4):319-25. doi: 10.1007/s004360050256. [PubMed: 9134552].

37. Dominguez-Marquez MV, Guna R, Munoz C, Gomez-Munoz MT, Borras R. High prevalence of subtype 4 among isolates of Blastocystis hominis from symptomatic patients of a health district of Valencia (Spain). Parasitol Res. 2009;105(4):949-55. doi: 10.1007/s00436-0091485-y. [PubMed: 19471964].

38. Yan Y, Su S, Lai R, Liao H, Ye J, Li X, et al. Genetic variability of Blastocystis hominis isolates in China. Parasitol Res. 2006;99(5):597-601. doi: 10.1007/s00436-006-0186-z. [PubMed:16688468].

39. Dogruman-Al F, Dagci H, Yoshikawa H, Kurt O, Demirel M. A possible link between subtype 2 and asymptomatic infections of Blastocystis hominis. Parasitol Res. 2008;103(3):685-9. doi: 10.1007/s00436-0081031-3. [PubMed: 18523804].

40. Jelinek T, Peyerl G, Löscher T, von Sonnenburg F, Nothdurft HD. The role of Blastocystis hominis as a possible intestinal pathogen in travellers. J Infect. 1997;35(1):63-6. doi:10.1016/s0163-4453(97)91025-2.

41. Moosavi A, Haghighi A, Mojarad EN, Zayeri F, Alebouyeh M, Khazan H, et al. Genetic variability of Blastocystis sp. isolated from symptomatic and asymptomatic individuals in Iran. Parasitol Res. 2012;111(6):2311-5. doi: 10.1007/s00436-012-3085-5. [PubMed: 22948205].

42. Motazedian H, Ghasemi H, Sadjjadi SM. Genomic diversity of Blastocystis hominis from patients in southern Iran. Ann Trop Med Parasitol. 2008;102(1):85-8. doi: 10.1179/136485908X252197. [PubMed: 18186983].

43. RostamiNejad M, Mousavi A, Nezamalhosseini Mojarad E. Blastocystis sp. subtype 2 cause of diarrhea in patient referred to GI clinic. Mol Med J. 2015;1(1):23-5.

44. Forsell J, Granlund M, Samuelsson L, Koskiniemi S, Edebro H, Evengard B. High occurrence of Blastocystis sp. subtypes 1-3 and Giardia intestinalis assemblage B among patients in Zanzibar, Tanzania. Parasit Vectors. 2016;9(1):370. doi: 10.1186/s13071-016-1637-8. [PubMed: 27356981]. [PubMed Central: PMC4928263]. 
45. Clark C. Extensive genetic diversity in Blastocystis hominis. Mol Biochem Parasitol. 1997;87(1):79-83. doi: 10.1016/s0166-6851(97)000467.

46. Tan TC, Suresh KG. Predominance of amoeboid forms of Blastocystis hominis in isolates from symptomatic patients. Parasitol Res. 2006;98(3):189-93. doi: 10.1007/s00436-005-0033-7. [PubMed: 16323025].

47. Ajjampur SS, Tan KS. Pathogenic mechanisms in Blastocystis spp. - Interpreting results from in vitro and in vivo studies. Parasitol Int. 2016;65(6 Pt B):772-9. doi: 10.1016/j.parint.2016.05.007. [PubMed: 27181702].

48. Zierdt $\mathrm{CH}$, Nagy B. Antibody response to Blastocystis hominis infections. Ann Intern Med.1993;118(12):985-6. doi:10.7326/0003-4819-118-12199306150-00018. [PubMed: 8489119].

49. Kukoschke KG, Muller HE. SDS-PAGE and immunological analysis of different axenic Blastocystis hominis strains. J Med Microbiol. 1991;35(1):35-9. doi: 10.1099/00222615-35-1-35. [PubMed: 1906543].

50. Gericke AS, Burchard GD, Knobloch J, Walderich B. Isoenzyme patterns of Blastocystis hominis patient isolates derived from symptomatic and healthy carriers. Trop Med Int Health.1997;2(3):245-53. doi: 10.1046/j.1365-3156.1997.d01-258.x. [PubMed: 9491103].

51. Müller HE. Four serologically different groups within the species Blastocystis hominis. Zentralblatt für Bakteriologie. 1994;280(3):403-8. doi: 10.1016/s0934-8840(11)80604-3.

52. Puthia MK, Vaithilingam A, Lu J, Tan KS. Degradation of human secretory immunoglobulin A by Blastocystis. Parasitol Res. 2005;97(5):3869. doi: 10.1007/s00436-005-1461-0. [PubMed: 16151742].

53. Moody S, Becker S, Nuchamowitz Y, Mirelman D. Virulent and avirulent Entamoeba histolytica and E. dispar differ in their cell surface phosphorylated glycolipids. Parasitology. 1997;114 ( Pt 2):95-104. doi: 10.1017/s0031182096008396. [PubMed: 9051918].

54. Chandramathi S, Suresh KG, Mahmood AA, Kuppusamy UR. Urinary hyaluronidase activity in rats infected with Blastocystis hominisevidence for invasion? Parasitol Res. 2010;106(6):1459-63. doi: 10.1007/s00436-010-1825-y. [PubMed: 20358228]

55. Teoh DA, Kamieniecki D, Pang G, Buret AG. Giardia lamblia rearranges F-Actin and a-Actinin in human colonic and duodenal monolayers and reduces transepithelial electrical resistance. J Parasitol. 2000;86(4):800. doi: 10.2307/3284967.

56. Hecht G, Pothoulakis C, LaMont JT, Madara JL. Clostridium difficile toxin A perturbs cytoskeletal structure and tight junction permeability of cultured human intestinal epithelial monolayers. J Clin Invest. 1988;82(5):1516-24. doi: 10.1172/JCI113760. [PubMed: 3141478]. [PubMed Central: PMC442717].

57. Walderich B, Bernauer S, Renner M, Knobloch J, Burchard GD. Cytopathic effects of Blastocystis hominis on Chinese hamster ovary (CHO) and adeno carcinoma HT29 cell cultures. Trop Med Int Health. 1998;3(5):385-90. doi: 10.1046/j.1365-3156.1998.00241.x. [PubMed: 9623944].

58. Long HY, Handschack A, Konig W, Ambrosch A. Blastocystis hominis modulates immune responses and cytokine release in colonic epithelial cells. Parasitol Res. 2001;87(12):1029-30. doi: 10.1007/s004360100494. [PubMed: 11763434].

59. Dagci H, Ustun S, Taner MS, Ersoz G, Karacasu F, Budak S. Protozoon infections and intestinal permeability.Acta Tropica. 2002;81(1):1-5. doi: 10.1016/s0001-706x(01)00191-7.

60. Pavanelli MF, Kaneshima EN, Uda CF, Colli CM, Falavigna-Guilherm AL, Gomes ML. Pathogenicity of Blastocystis sp. to the gastrointestinal tract of mice: Relationship between inoculum size and period of infection. Rev Inst Med Trop Sao Paulo. 2015;57(6):467-72. doi: 10.1590/S0036-46652015000600002. [PubMed: 27049699]. [PubMed Central: PMC4727131].

61. McKerrow JH, Sun E, Rosenthal PJ, Bouvier J. The proteases and pathogenicity of parasitic protozoa. Annu Rev Microbiol. 1993;47:821-
53. doi: 10.1146/annurev.mi.47.100193.004133. [PubMed: 8257117].

62. Silard R, Petrovici M, Panaitescu D, Stoicescu V. Blastocystis hominis in the liver of Cricetus auratus. Arch Roum Pathol Exp Microbiol. 1977;36(1):55-60.

63. Cirioni O, Giacometti A, Drenaggi D, Ancarani F, Scalise G. Prevalence and clinical relevance of Blastocystis hominis in diverse patient cohorts. Euro J Epidemiol. 1999;15(4):387-91. doi: 10.1023/a:1007551218671.

64. Zierdt $\mathrm{CH}$. Pathogenicity of Blastocystis hominis. J Clin Microbiol. 1991;29(3):662-3. doi: 10.1128/JCM.29.3.662-663.1991. [PubMed: 2037690]. [PubMed Central: PMC269843].

65. Leder K, Hellard ME, Sinclair MI, Fairley CK, Wolfe R. No correlation be tween clinical symptoms and Blastocystis hominis in immunocom petent individuals. J Gastroenterol Hepatol. 2005;20(9):1390-4. doi 10.1111/j.1440-1746.2005.03868.x. [PubMed:16105126].

66. Jupsa-Mbiandou S, Fosso S, Bille E, Melachio-Tanekou TT, AjeagahAghaindum G, Nana-Djeunga HC, et al. Pathogenicity and nonopportunistic character of Blastocystis spp.: a hospital-based survey in Central Cameroon. J Infect Dev Ctries. 2018;12(5):373-9. doi 10.3855/jidc.10122. [PubMed: 31865301].

67. Klesius PH, Haynes TB, Malo LK. Infectivity of Cryptosporidium sp isolated from wild mice for calves and mice. J Am Vet Med Assoc. 1986;189(2):192.

68. Sherwood D, Angus KW, Snodgrass DR, Tzipori S. Experimental cryptosporidiosis in laboratory mice. Infect Immun. 1982;38(2):471-5. doi: 10.1128/IAI.38.2.471-475.1982. [PubMed: 7141705]. [PubMed Central: PMC347763].

69. Wilson S, Roberts L, Roalfe A, Bridge P, Singh S. Prevalence of irritable bowel syndrome: a community survey. $\mathrm{Br} J$ Gen Pract. 2004;54(504):495-502.

70. Mohemmi N, Moradi M, Khalilian A, Maghsood AH, Fallah M. The relationship between blastocystis hominis infection and Irritable Bowel Syndrome (IBS) and comparing direct wet mount, stool culture, Formalin-Ether and trichrome staining procedures for identifying organisms. HMJ. 2015;19(2):77-84.

71. Mohammad Ali Gol S, Nabian S, Arabkhazaeli F, Mirjalali H, Bokaie S, Rezaeian M, et al. Study of Blastocystis frequency among IBD patients referred to a gastroenterology center. Iran J Vet Med. 2018;12(2):117-24.

72. Boorom KF, Smith H, Nimri L, Viscogliosi E, Spanakos G, Parkar U, et al. Oh my aching gut: irritable bowel syndrome, Blastocystis, and asymptomatic infection. Parasit Vectors. 2008;1(1):40. doi: 10.1186/17563305-1-40. [PubMed: 18937874]. [PubMed Central: PMC2627840].

73. Yakoob J, Jafri W, Jafri N, Khan R, Islam M, Beg MA, et al. Irritable bowel syndrome: in search of an etiology: role of Blastocystis hominis. Am J Trop Med Hyg. 2004;70(4):383-5. [PubMed: 15100450].

74. Gecse K, Roka R, Ferrier L, Leveque M, Eutamene H, Cartier C, et al Increased faecal serine protease activity in diarrhoeic IBS patients: a colonic lumenal factor impairing colonic permeability and sensitivity. Gut. 2008;57(5):591-9. doi: 10.1136/gut.2007.140210. [PubMed: 18194983].

75. Balint A, Doczi I, Bereczki L, Gyulai R, Szucs M, Farkas K, et al. Do not forget the stool examination!-cutaneous and gastrointestinal manifestations of Blastocystis sp. infection. Parasitol Res. 2014;113(4):158590. doi: 10.1007/s00436-014-3805-0. [PubMed: 24553977].

76. Dogruman-Al F, Simsek Z, Boorom K, Ekici E, Sahin M, Tuncer C, et al Comparison of methods for detection of Blastocystis infection in routinely submitted stool samples, and also in IBS/IBD Patients in Ankara, Turkey. PLoS One. 2010;5(11). e15484. doi:10.1371/journal.pone.0015484. [PubMed: 21124983]. [PubMed Central: PMC2987810].

77. Vogelberg C, Stensvold CR, Monecke S, Ditzen A, Stopsack K, HeinrichGrafe $U$, et al. Blastocystis sp. subtype 2 detection during recurrence of gastrointestinal and urticarial symptoms. Parasitol Int. 2010;59(3):469-71. doi: 10.1016/j.parint.2010.03.009. [PubMed: 20363362]. 